José Gesto Rodríguez*

\title{
Repensando un nuevo modelo ciudad post-COVID-19
}

\section{Cómo citar:}

Gesto, J (2020). Repensando un nuevo modelo ciudad post-COVID19 Designia, 8(2), 9-25.

\author{
* Doctor en Gobierno y Administración Pública, ELCPAPO, México. \\ Departamento de Investigación de la Universidad Abierta de Tlaxcala, A.C. \\ E-mail: campus.off@gmail.com \\ ORCID: https://orcid.org/0000-0001-9396-6020
}

\section{Palabras clave:}

Ciudad, urbanismo, desarrollo urbano, pandemia, COVID-19.

\section{Key words:}

City, urbanism, urban development, pandemic, COVID-19.

\section{Resumen:}

En la actualidad, muchos investigadores están enfocados en la exploración de la dinámica de la pandemia en las áreas urbanas para la comprensión de sus impactos en las ciudades. Ciertamente, esta crisis sanitaria ha dejado una huella indeleble en la cotidianidad de los grandes asentamientos humanos, obligando a repensar el desarrollo de los mismos en diferentes dimensiones. Particularmente, la disciplina urbanística tiene el reto de generar novedosos modelos que logren mantener el equilibrio entre el nuevo concepto de distanciamiento social y las propuestas que combinen el esfuerzo creativo, así como el adecuado uso de los recursos disponibles en la lucha contra el COVID-19 y otras afectaciones futuras. A continuación se hace un análisis de literatura científica reciente; mediante la revisión de referenciales teóricos que muestran cómo las ciudades pueden repensar sus políticas urbanas para fortalecer su preparación ante riesgos y su capacidad de respuesta, y volverse más resilientes, inteligentes, sostenibles e inclusivas. 


\section{Abstract:}

At present, many researchers are focused on exploring the dynamics of the pandemic in urban areas to understand its impacts on cities. Certainly, this health crisis has left an indelible mark on the daily life of large human settlements, forcing us to rethink their development in different dimensions. In particular, the urban discipline has the challenge of generating novel models that manage to maintain the balance between the new concept of social distancing and the proposals that combine creative effort, as well as the adequate use of available resources in the fight against COVID-19 and other future impacts. The following is an analysis of recent scientific literature; by reviewing theoretical benchmarks that show how cities can rethink their urban policies to strengthen their risk preparedness and response capacity, and become more resilient, smart, sustainable and inclusive.

\section{INTRODUCCIÓN}

En el mundo contemporáneo, las ciudades reclaman una respuesta sostenible y adecuada a sus problemáticas, asociadas principalmente a las necesidades de la vida cotidiana, al aseguramiento de su calidad ambiental y al nivel de salubridad de sus espacios (Arboleda y Bedoya, 2018; Fauth y Lunardelli, 2018; Molpeceres, 2017; Rodríguez, 2020a). No obstante, ante la crisis sanitaria que experimenta la sociedad, la disciplina urbanística deberá considerar adicionalmente para la satisfacción de tales demandas, la nueva variable que representa el COVID-19; lo que obliga a repensar en un nuevo modelo de concentraciones urbanas (Cuerdo, 2020; Mardones et al., 2020).

En efecto, el abordaje de la actual pandemia, así como las transformaciones que se generarán en las ciudades tras la crisis epidemiológica del COVID-19, suscitan la necesidad de la realización de un análisis profundo del desarrollo de las mismas, con un enfoque interdisciplinar y multisectorial, involucrando la integración de “variables culturales, económicas y sociales propias de los sectores poblacionales más vulnerables que se verán afectados por los efectos negativos del virus en asentamientos humanos de origen informal"; siendo esta, una situación que implica 
la consideración de una visión científica de la arquitectura, además de la revisión de diversos aspectos de la salud pública, en los que la ciudad y la política pública, deberán reorientar sus objetivos hacia el cuidado de sus habitantes, con el propósito de "reducir las consecuencias patógenas de la densidad urbana en áreas de origen informal con procesos de consolidación urbana" (Vargas, 2020, p. 38).

$\mathrm{Al}$ presente, la emergencia sanitaria de interés internacional, declarada por la Organización Mundial de la Salud (OMS) en enero de 2020 (Organización Panamericana de la Salud [OPS], 2020) ha propiciado el cuestionamiento de los modelos de desarrollo urbano y la planificación de las ciudades desde nuevas dimensiones y perspectivas (López, 2020; Gutiérrez, 2020; Rodríguez, 2020b; Rojas, 2020; Xu, 2020; Zamorano, 2020); todo ello, en función de que "la movilidad de las personas y reestructuraciones de relaciones sociales, productivas y de consumo se sitúan en el centro de un problema de salud pública con dimensiones inéditas" (Mattioli y Schneider, 2020, p. 340).

De allí, que la alta transmisibilidad del SARS-CoV-2, -las siglas en inglés de Severe Acute Respiratory Syndrome Coronavirus (BBC News Mundo, 2020)- obliga a que la prevención del contagio en el contexto de las grandes ciudades, "enfrente el desafío de los principales factores de dispersión: la alta densidad poblacional, la elevada cantidad de desplazamientos de personas y la influencia de las centralidades sobre los territorios circundantes" (Mattioli y Schneider, 2020, p. 340). Mundialmente, al presente están siendo discutidas las nuevas condiciones requeridas para las intervenciones en el diseño de los centros urbanos, "por lo que pensar en escenarios de transformaciones puntuales respecto a estas locaciones de las necesidades y déficits, atenderían a la emergencia" (p. 344). A continuación, se hace una revisión de los aspectos más resaltantes de las consideraciones en torno a los urbanismos en el siglo XXI, durante y tras la finalización de la pandemia por COVID-19.

\section{MARCO TEÓRICO}

\section{Las ciudades en el contexto del COVID-19}

En la actualidad, "las zonas urbanas son la zona cero de la pandemia del COVID-19, con un 90\% de los casos comunicados" (Guterres, 2020, párr. 1). El tamaño de sus poblaciones, así como su alto nivel de interconectividad global y local, las hacen particularmente vulnerables a la propagación del virus; sin embargo, no hay evidencia que sugiera que la densidad por sí misma, esté correlacionada con una mayor transmisión de este (Organización de las Naciones Unidas [ONU], 2020). La evidencia reportada hasta el momento, sobre la asociación entre densidad y el COVID-19, es contrastante y no concluyente (Boterman, 2020; Carteni et al., 2020; Connolly et al., 2020; Hamidi et al., 2020; Lin et al., 2020; Qiu et al., 2020; Ren et al., 2020). Pese a ello, pudiera afirmarse que "las ciudades están sufriendo las peores 
consecuencias de la crisis, muchas de ellas con sistemas de salud sobrecargados, servicios de agua y saneamiento inadecuados y otros problemas"; lo cual se ha hecho aún más evidente en las áreas más pobres, "donde la pandemia ha puesto de manifiesto desigualdades profundamente arraigadas" (Guterres, 2020).

En tal sentido, Lampis (2013) destaca que el escenario de riesgo y vulnerabilidad social de la población urbana tiende aumentar en la medida en que esta no dispone de las capacidades para lograr la prevención, enfrentamiento y recuperación de eventos críticos, vinculados a la pérdida de activos materiales y capital social, frente a algún evento detonante, que tienda a vulnerar su capacidad de resiliencia; lo cual conlleva a una exposición al riesgo de las personas ante las amenazas físicas y sociales del entorno, representadas en los tiempos actuales, por la pandemia de la enfermedad COVID-19 (Vargas, 2020). A corto plazo, para muchas ciudades, la crisis de salud se ha expandido a una crisis de acceso urbano, equidad y finanzas urbanas, seguridad, desempleo, servicios públicos, infraestructura y transporte; afectando con ello, desproporcionadamente, a los más vulnerables de la sociedad (ONU, 2020). Al respecto, Nieuwenhuijsen (2020), agrega que:

\begin{abstract}
Las ciudades son centros de innovación y de creación de riqueza, pero también puntos críticos en contaminación del aire y ruido, efectos de la isla de calor y falta de espacios verdes [...]. También son puntos críticos para la COVID-19. Las ciudades son sistemas complejos que atraen a las personas por su oferta laboral, su ecosistema social, sus eventos y sus oportunidades ilimitadas [...]; se caracterizan por un estrecho contacto personal y marcadas desigualdades, aspectos que se han vuelto más evidentes a causa de la COVID-19.
\end{abstract}

Una de las principales medidas aplicadas por distintos gobiernos en todo el mundo ante la emergencia sanitaria, ha sido el aislamiento social preventivo y obligatorio orientado a lograr la mitigación de los contagios, así como el distanciamiento social, entre otras acciones que implican un compromiso colectivo para garantizar la minimización de los decesos y acelerar la pronta salida de esta crisis. “En consonancia, se reflejan en el territorio, complejas relaciones y fenómenos, donde la desigualdad socioeconómica y las disparidades en el acceso al bienestar de la población en cada lugar de residencia, plantean nuevos retos para el sostenimiento de la vida" (Mattioli y Schneider, 2020).

Si bien el vínculo entre la prevalencia de COVID-19 y las características del diseño urbano ha creado muchos debates en los medios y el público, las investigaciones recientes no especifican con mucho detalle cómo las diferentes medidas de diseño, entre las que destacan la conectividad, el tamaño del bloque, la combinación de usos 
del suelo, el policentrismo, etcétera, influyen en la tasa de infección y mortalidad de COVID-19 y en la capacidad de las ciudades para responder a la pandemia. Sin embargo, de acuerdo con los primeros hallazgos, los estudios recomiendan a los planificadores que sigan abogando por formas compactas de desarrollo urbano, en lugar de extensivas; puesto que en la literatura científica se demuestra la diversidad de méritos de estas tipologías (Connolly et al., 2020; Hamidi et al., 2020; Sharifi, 2019a, Sharifi, 2019b).

\section{Repensando las urbes tras la pandemia}

Desde los primeros días de la crisis suscitada mundialmente a causa del COVID-19, la comunidad científica se ha esforzado constantemente por dilucidar sobre diversos temas, entre ellos, los mecanismos que impulsan la propagación del virus, sus impactos ambientales y socioeconómicos, así como los planes y políticas de recuperación y adaptación necesarios (OMS, 2020a, 2020b; Organización de las Naciones Unidas para la Educación, la Ciencia y la Cultura [UNESCO] (2020); Programa de las Naciones Unidas para el Desarrollo [PNUD], 2020; Programa de las Naciones Unidas para el Medio Ambiente [PNUMA], 2020). La alta concentración de la población y de actividades económicas en las ciudades, genera que estas sean consideradas focos sensibles de infecciones; en consecuencia, muchos especialistas están explorando la dinámica de la pandemia en áreas urbanas para comprender sus impactos al interior de las mismas (Sharifia y Khavarian, 2020).

\footnotetext{
Las ciudades se ven profundamente afectadas por la pandemia de COVID-19, que plantea cuestiones fundamentales sobre el desarrollo urbano sostenible y simbiótico. El carácter multidimensional de la pandemia ha dejado una huella indeleble en el panorama de las ciudades y ha llevado a repensar el desarrollo de las ciudades en diferentes dimensiones: social, cultural, económica y ambiental. Al estar a la vanguardia, las ciudades han jugado un papel central en la respuesta global a la pandemia en curso. (UNESCO, 2020, párr. 1)
} 
El análisis de estas consideraciones hace evidente la necesidad urgente de repensar y transformar las ciudades para responder a la realidad del COVID-19 y a posibles pandemias futuras, con una mejor capacidad de recuperación; de allí, que se requiera la construcción de urbes más resilientes, inclusivas y sostenibles (ONU, 2020).

\begin{abstract}
La pandemia COVID-19, es un punto de inflexión disciplinar, para reconocer el territorio y la diversidad de formas en que las personas y grupos sociales se hacen a un espacio. La ciudad informal, a pesar de sus incongruencias legales, guarda en esencia lógicas de apropiación y construcción social del hábitat en nuestras ciudades, y deben ser asumidas como un reto de investigación y praxis profesional, que hagan de estos asentamientos humanos espacios más resilientes ante cualquier eventualidad, que ponga en riesgo la vida de quienes los construye. (Vargas, 2020, p. 38)
\end{abstract}

De forma inexorable, la crisis sanitaria mundial ha obligado a la humanidad a repensar su relación con el espacio, así como la relación que los individuos pueden entretener los unos con los otros en el entorno urbano. Para ello, habrá que redefinir:

[...] no sólo la manera de estar en el espacio sino imaginar espacios de otro tipo y de otro tamaño, que respondan de forma más adecuada a la necesidad del distanciamiento físico y que permitan seguir viviendo en la ciudad, disfrutando la presencia de los otros, pero evitando la experiencia de la inmersión en la multitud. (Giglia, 2020, p. 294)

Indudablemente, la forma en la que son concebidos los centros urbanos y su espacio público, cambiarán después de la pandemia provocada por el COVID-19. En tal sentido, para Chávez (2020, p. 2), las ciudades se enfrentan a dos grandes retos: en el campo arquitectónico-habitacional, señala que las viviendas se transformarán en espacios, donde además de las actividades usuales, los individuos puedan trabajar, ejercitarse, aprender, jugar, relajarse y desarrollar la mayoría de sus necesidades; asimismo, en el campo urbanístico, indica que el reto consistirá en "lidiar con las concentraciones de personas, el fomento del distanciamiento social y las condiciones de higiene y limpieza de los espacios públicos y sus elementos urbanos", puesto que es en estos últimos donde se intensifica y se hace posible el estar en contacto con enfermedades infecciosas y donde también pueden ser transmitidas con mayor facilidad. 
La crisis del COVID-19 ha generado un período de reinvención en todos los ámbitos de la vida cotidiana. Especialmente, respecto a la infraestructura y distribución de espacios como viviendas y lugares públicos (restaurantes, comercios, bancos, etc.), que deben adaptarse a los requerimientos y nuevas medidas sanitarias. Frente a este escenario, aspectos como espacios abiertos y flexibles, calidad de los materiales, productos de construcción más sostenibles y el uso de nuevas tecnologías están cobrando cada vez mayor relevancia en la industria. (Bouverie, 2020, párr. 2)

\section{Nuevos modelos urbanos en el siglo XXI}

Los esfuerzos para detener la propagación del coronavirus están generado intervenciones de diseño novedosas y creativas, que salvan vidas en las grandes ciudades (OMS, 2020c; OVACEN, 2020; Waller y Chakrabarti, 2020). Según Mardones et al. (2020), la pandemia del COVID-19 constituye una oportunidad sin precedentes, tanto desde el punto de vista económico como de opinión, de recuperar la llamada "ciudad de la proximidad" donde el valor de lo local, en contraste a la globalización, ha quedado patente. En tal sentido, ha de entenderse que:

\begin{abstract}
Las escalas de aproximación académica tienen que revaluar aspectos como el espacio privado de la vivienda y sus relaciones con el cuidado del cuerpo, así como las relaciones de proximidad de las edificaciones, zonas barriales, las ciudades en toda su extensión (legal y no legal) y las relaciones con la globalidad del territorio que la circunda y de donde obtiene los recursos naturales que la dinamizan. (Vargas, 2020, p. 38)
\end{abstract}

En consonancia con estas preocupaciones, han surgido diversas propuestas, entre ellas, la "ciudad del cuarto de hora" generada por la Alcaldía de la París (García, 2020; Llorente, 2020) en Francia, la cual apuesta por una ciudad de proximidad basada en el concepto del cronourbanismo (Moreno, 2020; citado por Moro y Valdés, 2020), donde lo esencial es disponer de todo lo que se necesita a menos de quince (15) minutos desde la vivienda, a pie o en bicicleta. Este modelo, pareciera ofrecer no solamente una respuesta sostenible a los problemas que venían arrastrando las urbes, "sino que, desde la inmediatez de los hechos, parece una primera respuesta válida a la crisis sanitaria mundial" que experimenta la sociedad (Mardones et al., 2020, p. 654).

Siguiendo esta misma línea, Córdoba et al. (2020) plantean un estudio centrado en las calzadas de la ciudad de Madrid, España, bajo la consideración de que la capacidad del espacio libre, -que permita tanto la circulación como el resto de usos que en este, normalmente se desarrollan, manteniendo una distancia segura entre personas-, es uno de los factores de la resiliencia urbana de mayor importancia a tener en cuenta, dada la emergencia sanitaria. Consecuentemente, el obligado y 
necesario confinamiento mundial, ha puesto en evidencia "la necesidad de repensar el espacio público de cara a retomar paulatinamente la utilización de la vía pública y los numerosos usos que en ella se realizan" (párr. 1). De allí que "se ha empezado a actuar en diferentes ciudades, una transformación a través de nuevos diseños de calles y estrategias de recuperación del espacio ocupado por el automóvil con el fin de asegurar que desigualdades y desafíos ya existentes desaparezcan" (párr. 4).

Por su parte, Rojas y Morales (2020) sugieren lo que han denominado "urbanismo táctico" (Figura 1), el cual consiste en una "intervención temporal de bajo costo que se puede implementar rápidamente en ciudades de cualquier tamaño"; no obstante, "muchas de estas intervenciones pueden hacerse permanentes para favorecer las mejoras urbanas y la salud pública" (p. 1). Entre las acciones más destacadas, pueden mencionarse las siguientes (Rojas, 2020): seguir las recomendaciones generales de distanciamiento físico en espacios públicos; expandir las aceras y los carriles para bicicletas; poner en funcionamiento ciclovías recreativas; adaptar parques y espacios públicos, así como los semáforos, la señalización y los límites de velocidad; adaptar el transporte público, la micromovilidad compartida y los vehículos compartidos; concentrar el tráfico motorizado; adaptar los comercios esenciales; proporcionar acceso no motorizado a los centros donde se realizan pruebas de COVID-19; adaptar los servicios y centros de acogida para las personas sin hogar.

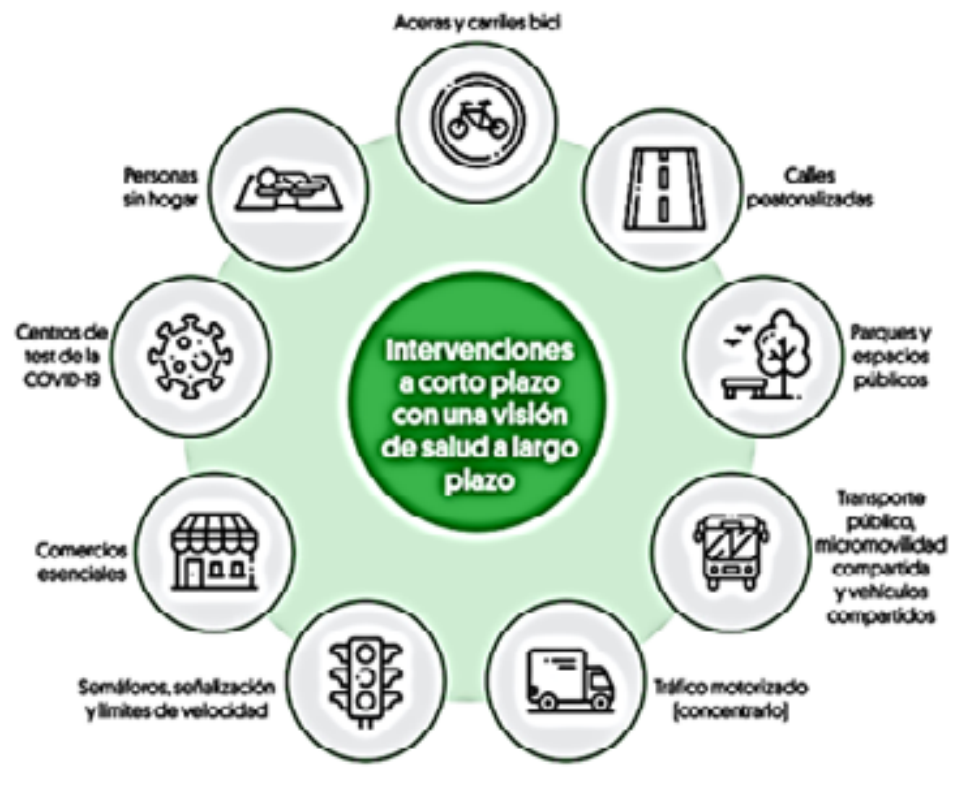

Figura 1. Urbanismo táctico para COVID-19. Fuente: Rojas y Morales (2020). 
Otra iniciativa, que ha demostrado responder efectivamente ante la pandemia, es la de la llamada "ciudad funcional", entendida como aquella donde los sistemas de gobernanza y prestación de servicios funcionan a la perfección, de forma eficaz y simultánea en una variedad de dimensiones: es una ciudad que ofrece servicios públicos de alta calidad para todas las personas, tanto en barrios ricos como pobres; que trabaja duro para crear oportunidades económicas para residentes y negocios; que prioriza la participación comunitaria y la inclusión para todos, y que toma políticas y decisiones que crean una vida estimulante y agradable para sus residentes (Wahba y Vapaavuori, 2020). Algo quizás, utópico para algunas regiones, pero no imposible.

Análogamente, Nieuwenhuijsen (2020), hace mención a la "ciudad compacta", caracterizada por una mayor densidad residencial, distancias de viaje más cortas y una mayor diversidad en el uso del suelo, con trayectos más cortos y oportunidades de movilidad más saludables. Este autor destaca también como otros conceptos de planificación novedosos: las supermanzanas, orientadas a la reducción del tráfico motorizado dentro de algunas de sus calles, dedicando así más espacio a las personas, los desplazamientos activos y los espacios verdes; la ciudad de 15 minutos (ya descrita); la ciudad sin coches, con el objetivo declarado de reducir las emisiones de gases de efecto invernadero; o una combinación de estos. "Todos estos nuevos modelos urbanos tienen en común que invierten la pirámide de planificación del transporte para que, en lugar de priorizar los automóviles, los planificadores urbanos prioricen el transporte público, caminar e ir en bicicleta" (párr. 13).

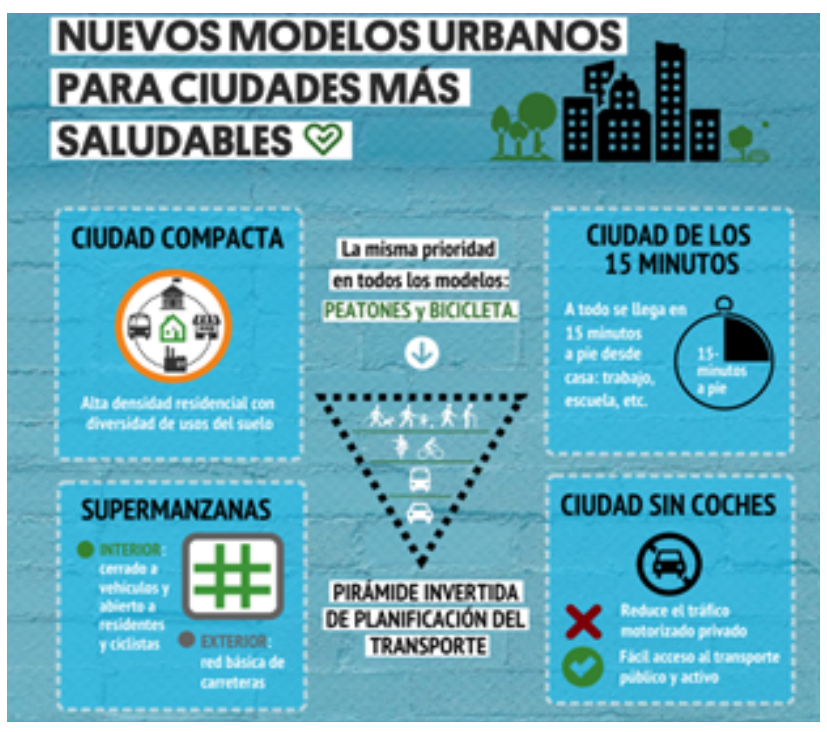

Figura 2. Nuevos modelos urbanos para ciudades más saludables. Fuente: Nieuwenhuijsen (2020). 
De una forma concreta, debe asumirse que tales propuestas para la transformación de las ciudades tendrán que cambiar muchos conceptos tradicionales, en aras de garantizar la protección de los ciudadanos. Atendiendo a ello, ha sido publicada una guía urbanística por la National Association of City Transportation Officials (NACTO, 2020), la cual compila las prácticas emergentes en todo el mundo e incluye recursos que las ciudades y sus aliados podrán usar para implementarlas. Específicamente, este documento aglutina a 81 grandes ciudades y agencias de movilidad con el propósito de intercambiar ideas y prácticas de transporte que permitan abordar de manera cooperativa la crisis ante la pandemia y facilitar la recuperación económica, haciendo alusión a los aspectos que a continuación se describen, y para los cuales, se emiten recomendaciones específicas:

- Servicios críticos: se deberá proporcionar espacio para los centros de distribución de servicios alimenticios, de limpieza pública, de salud, médicos o sociales centrales y/o temporales.

- Gestión de la velocidad de los vehículos: para incrementar la seguridad brindada a todos los usuarios en las calles.

- Extensiones de la acera: que permitan a las personas el cumplimiento de las indicaciones de distanciamiento físico mientras caminan o esperan en fila.

- Cruces peatonales seguros: que garanticen el que se pueda caminar o andar en bicicleta sin riesgo alguno, dado el mayor volumen de tránsito y los cambios en los patrones de viaje.

- Calles de tráfico lento: se sugiere reducir el volumen y la velocidad del tráfico al mínimo nivel, para la seguridad de peatones, ciclistas, corredores, etcétera.

- Calles abiertas y/o para jugar: se deberá proporcionar un espacio seguro para la actividad física, el juego, la socialización a distancia, etcétera.

- Carriles para andar en bicicleta y patinar: los trabajadores esenciales y otras personas deberán disponer de espacio suficiente para andar en bicicleta y patinar con seguridad mientras se mantiene la distancia física necesaria.

- Carriles para el transporte público: deberá considerarse la asignación o ampliación de los carriles de uso exclusivo o prioritario para el transporte público, de tal manera que este se constituya en un medio de traslado confiable y eficiente. 
- Paradas y acceso al transporte público: se exige un espacio suficiente para la espera del transporte público, así como para permitir el ascenso por la puerta trasera o por cualquier puerta; reduciéndose con ello, el tiempo de espera en fila y de ascenso de pasajeros.

- Áreas de retiro y entrega: se sugiere la adaptación de los espacios de estacionamiento junto a la acera o los carriles de circulación, para convertirlos en zonas de retiro o entrega de alto movimiento para los servicios esenciales.

- Comidas al aire libre: deberá existir el espacio necesario para que se pueda comer al aire libre, de forma tal que los restaurantes puedan dar cumplimiento con las indicaciones de distanciamiento físico.

- Mercados: los cuales serán extendidos hacia las calles adyacentes con el objeto de aliviar las aglomeraciones y permitir el distanciamiento físico.

- Calles y escuela: los espacios escolares y recreativos deben ser amplios, al aire libre, con demarcación de zonas seguras para dejar y recoger a los niños, así como para los controles de salud.

- Calles para protestas: habrá que proporcionar facilidades de acceso seguro a los espacios públicos para que los ciudadanos puedan ejercer el derecho civil fundamental de manifestarse y protestar.

- Reuniones y eventos: una alternativa viable, es el uso de cierres totales o parciales de calles que ofrezcan espacio al aire libre para reuniones culturales, religiosas o cívicas.

La guía en referencia, "ofrece tanto tratamientos concretos, de respuesta rápida y basados en el diseño, como ejemplos prácticos de actuaciones urbanísticas para ayudar a las ciudades a actuar de forma responsable y equitativa mientras se trabaja para transformar el entorno construido" (OVACEN, 2020, párr. 2). Se consideran en ella, esencialmente, los siguientes aspectos: la valoración de la pertinencia de una distancia física, manteniendo el equilibrio entre el tránsito vial y peatonal; la necesidad del establecimiento de principios básicos de recuperación que guíen las inversiones económicas y la toma de decisiones; la reestructuración de las calles de forma rápida como una respuesta evolutiva ante la crisis; y finalmente, una nueva visión de las aceras, como uno de los elementos urbanísticos más susceptibles de transformación (NACTO, 2020). 
En general, el conocimiento existente en la literatura científica actual, muestra que la crisis de COVID-19 representa una excelente oportunidad para que los planificadores y los responsables políticos promuevan acciones transformadoras hacia la creación de ciudades más justas, resilientes y sostenibles (Sharifia y Khavarian, 2020). En alusión a ello, la ONU (2020) considera que ciertamente, "las ciudades pueden gestionar esta crisis y emerger como centros de energía, resiliencia e innovación que las convierten en lugares tan vibrantes y atractivos para que muchos vivan"; para lo cual, se requerirá de la toma decisiones políticas conscientes, que tengan en consideración aspectos como "las desigualdades, las capacidades locales y una recuperación verde e inclusiva” (p. 2).

La comprensión de la necesidad de implantación de una nueva generación de políticas desde una perspectiva de justicia espacial y enfocada en los derechos humanos, permitirá la renovación de la política de valor que subyace a los procesos de producción social del espacio; asimismo, promoverá el fortalecimiento del papel del Estado como protector y garante de los derechos civiles, lo cual conducirá hacia una nueva praxis política que considere la inclusión de los mismos en los procesos de planificación y gestión urbana (Guevara, 2020).

\section{CONCLUSIONES}

El notable crecimiento de las ciudades en las últimas décadas ha intensificado varios de los desafíos más urgentes de la humanidad. También ha significado una oportunidad para poner a prueba la protección que las condiciones urbanas pueden ofrecer a las personas y al planeta, en aras además, de contribuir al desarrollo sustentable. El COVID-19 ha puesto al descubierto, y de hecho aumentado, tanto estos desafíos como estas oportunidades.

La actual crisis epidemiológica ha suscitado el replanteo de los estándares de diseño urbano, atendiendo a una multiplicidad de variables de índole diversa, en combinación con las directrices para el mantenimiento de la salud pública. De allí que la planificación de las ciudades deba ser evaluada desde nuevas dimensiones y perspectivas.

Indudablemente, el COVID-19 ha representado un reto para la investigación y praxis profesional en el desarrollo de modelos de concentraciones urbanas resilientes, inclusivas, sostenibles, seguras, y sobre todo, saludables. La relación entre los individuos y el espacio, el manejo de las relaciones sociales, así como las condiciones de habitabilidad y movilidad dentro del entorno urbano, ocupan un lugar destacado en la reinvención de las ciudades, así como en todos los ámbitos de la vida cotidiana. 


\section{REFERENCIAS BIBLIOGRÁFICAS}

Arboleda, J. y Bedoya, F (2018). “Repensar la ciudad. Hacia una acupuntura urbana”. Dearq, Nro. 28, pp. 48-59. Consultado el 27 de noviembre de 2020 de: https://doi.org/10.18389/dearq28.2020.05

BBC News Mundo (20 de marzo, 2020). “Coronavirus: qué significan los términos que usamos con más frecuencia al hablar de la pandemia de covid-19". Consultado el 27 de noviembre de 2020 de: https:// www.bbc.com/mundo/noticias-51969328

Bouverie, J. (2020). "Los retos de la arquitectura y el urbanismo post COVID-19". Dossier. Consultado el 27 de noviembre de 2020 de: https://dossierdearquitectura.com/post/ los-retos-de-la-arquitectura-y-el-urbanismo-post-covid-19-5f32a57062fab

Boterman, W. (2020). "Urban-rural polarisation in times of the corona outbreak? The early demographic and geographic patterns of the SARS-CoV-2 epidemic in the Netherlands". Tijds. voor econ. en Soc. Geog., Vol. 111, pp. 513-529. doi: 10.1111/tesg.12437.

Carteni, A., Di Francesco, L. \& Martino, M. (2020). "How mobility habits influenced the spread of the COVID-19 pandemic: results from the Italian case study". Sci. Total Environ, Vol. 741, Nro. 40489.

Chávez, O. (6 mayo, 2020). “Urbanismo y ciudades post covid-19”. Omnia. Consultado el 27 de noviembre de 2020 de: http: http://www.omnia.com.mx/noticia/14244

Connolly, C.; Ali, S. \& Keil, R. (2020). “On the relationships between COVID-19 and extended urbanization”. Dial. Hum. Geogr., Vol. 10, Nro. 2; pp. 213-216.

Córdoba, R.; Fernández, C.; González, I.; Díez, A. y Álvarez, L. (2020). “Hacia la Ciudad de los 15 minutos frente al COVID19 (III). La capacidad de actuación sobre las calzadas de Madrid durante la desescalada". Crisis Urbana, Rehabilitación y Regeneración. Consultado el 03 de diciembre de 2020 de: http://vps181.cesvima.upm.es/re-hab/2020/05/28/hacia-la-ciudad-de-los-15-minutos-frenteal-covid19-iii-la-capacidad-de-actuacion-sobre-las-calzadas-de-madrid-durante-la-desescalada/

Cuerdo, M. (2020). "Repensar la vivienda tras la pandemia". The Conversation. Consultado el 27 de noviembre de 2020 de:

https://digital.csic.es/bitstream/10261/211231/1/Repensar\%20la\%20vivienda\%20tras\%201a\%20 pandemia.pdf

Fauth, G. y Lunardelli, R. (2018). “Desafíos jurídico-urbanísticos en el enfrentamiento del cambio climático en las ciudades". Desafíos de la Acción Jurídica Internacional y Europea frente al cambio climático, pp. 99-111 
García, A. (29 de enero, 2020). “La promesa estrella de la alcaldesa de París: que nadie tarde más de 15 minutos en ir al trabajo o al colegio". El Diario.es. Consultado el 27 de noviembre de 2020 de: https://www. eldiario.es/internacional/promesa-estrella-alcaldesa-paris-servicios_1_1067256.html\#: :text=Bajo\%20 el\%20nombre\%20’La\%20Ville,a\%20pie\%20como\%20en\%20bicicleta.

Giglia, A. (2020). "Repensar las ciudades desde el encierro doméstico". En: Delgado, G. y López, D. Las ciudades ante el COVID-19: nuevas direcciones para la investigación urbana y las políticas públicas. México: Plataforma de conocimiento para la Transformación Urbana. Consultado el 27 de noviembre de 2020 de: www.transformacionurbana.mx

Guevara, J. (2020). “Justicia espacial y habitar digno. La pandemia como punto de partida para una nueva generación de políticas públicas territoriales". En: Delgado, G. y López, D. “Las nuevas ciudades ante el COVID-19: nuevas direcciones para la investigación urbana y las políticas públicas". Plataforma de conocimiento para la Transformación Urbana, International Network for Government Science Advice.

Guterres, A. (2020). "El impacto de la pandemia en las ciudades". Organización de las Naciones Unidas: COVID-19 Respuesta. Consultado el 27 de noviembre de 2020 de: https://www.un.org/es/coronavirus/articles/ covid-19-urban-world

Gutierres, J. (2020). “Ciudades Ideales en la Pos-pandemia”. LA Network. Consultado el 27 de noviembre de 2020 de: https://la.network/ciudades-ideales-en-la-pos-pandemia/

Hamidi, S.; Sabouri S. \& Ewing, R. (2020). “Does density aggravate the COVID-19 pandemic?: early findings and lessons for planners". J. Am. Plan. Assoc. Consultado el 27 de noviembre de 2020 de: https://www.tandfonline.com/doi/full/10.1080/01944363.2020.1777891

Lampis, A. (2013). “Vulnerabilidad y adaptación al cambio climático: debates acerca del concepto de vulnerabilidad y su medición". Cuadernos de Geografía, Revista Colombiana de Geografía, Vol. 22, Nro. 2, pp. 17-33.

Lin, C.; Lau, A.; Fung, J.; Guo, C.; Chan, J.; Yeung, D.; Zhang, Y.; Bo, Y.; Hossain, M.; Zeng, Y. \& Lao, X. (2020). "A mechanism-based parameterisation scheme to investigate the association between transmission rate of COVID-19 and meteorological factors on plains in China". Sci. Total Environ, Vol. 737.

López, G. (2020). "Repensar las ciudades y sus arquitecturas". Arquine. Consultado el 27 de noviembre de 2020 de: https://www.arquine.com/repensar-las-ciudades-y-sus-arquitecturas/

Llorente, A. (2020). “Coronavirus en Francia: qué es la "ciudad de 15 minutos” que está implementando París y cómo podría ayudar a la recuperación económica tras la pandemia". BBC News. Consultado el 27 de noviembre de 2020 de: https://www.bbc.com/mundo/noticias-53589225 
Mardones, N.; Valdiva, J. y Aseguinolaza, I. (2020). “La ciudad del cuarto de hora, ¿una solución sostenible para la ciudad postCOVID-19?". Ciudad y territorio, Estudios territoriales, Vol. LII, Nro. 2020, pp. 653-664. Consultado el 23 de noviembre de 2020 de: https://doi.org/10.37230/CyTET.2020.205.13.1

Mattioli, L. y Schneider, M. (2020). “Redefiniendo nuestro futuro. La transformación de nuestras ciudades frente a la crisis COVID-19”. En: Delgado, G. y López, D. “Las nuevas ciudades ante el COVID-19: nuevas direcciones para la investigación urbana y las políticas públicas". Plataforma de conocimiento para la Transformación Urbana, International Network for Government Science Advice.

Molpeceres, C. (2017). "Repensando el territorio en el fin del mundo: Transformaciones urbanas en Ushuaia”. Investigación +Acción, Nro. 20, pp. 77-100. Consultado el 27 de noviembre de 2020 de: https://revistasfaud.mdp.edu.ar/ia/article/view/IA20-04/161

Moro, B. y Valdés, F. (05 de marzo, 2020). “Carlos Moreno: La ciudad del cuarto de hora es cambiar el paradigma de la ciudad moderna". Rfi. Consultado el 27 de noviembre de 2020 de: https://www.rfi. fr/es/carlos-moreno-la-ciudad-del-cuarto-de-hora-es-cambiar-el-paradigma-de-la-ciudad-moderna

National Association of City Transportation Officials [NACTO] (2020). "Streets for Pandemic Response \& Recovery". Consultado el 03 de diciembre de 2020 de: https://nacto.org/publication/ streets-for-pandemic-response-recovery/

Nieuwenhuijsen, M. (20 de octubre, 2020). "Ciudades post-COVID-19: nuevos modelos urbanos para que las ciudades sean más saludables". Instituto de Salud Global de Barcelona. Consultado el 23 de noviembre de 2020 de: https://www.isglobal.org/healthisglobal/-/custom-blog-portlet/ post-covid-19-cities-new-urban-models-to-make-cities-healthier/4735173/0

Organización de las Naciones Unidas [ONU] (2020). "Policy Brief: COVID-19 in an Urban World". Consultado el 25 de noviembre de 2020 de: https://www.un.org/sites/un2.un.org/files/covid-19_in_an_urban_world_spanish.pdf

Organización de las Naciones Unidas para la Educación, la Ciencia y la Cultura [UNESCO] (2020). "Solutions urbaines: s'inspirer de l'action des villes face à la COVID-19: rapport de la réunion en ligne". Consultado el 27 de noviembre de 2020 de: https://unesdoc.unesco.org/ark:/48223/ pf0000373940_fre?posInSet=1\&queryId=N-EXPLORE-635a0cbb-8c83-4bd9-9544-974306d26466

Organización Mundial de la Salud [OMS] (2020a). "Actualización de la estrategia frente a la COVID-19". Consultado el 27 de noviembre de 2020 de: https://www.who.int/docs/default-source/coronaviruse/ covid-strategy-update-14april2020_es.pdf 
Organización Mundial de la Salud [OMS] (2020b). “Vías de transmisión del virus de la COVID-19: repercusiones para las recomendaciones relativas a las precauciones en materia de prevención y control de las infecciones". Consultado el 27 de noviembre de 2020 de: https:/www.who.int/es/news-room/commentaries/detail/ modes-of-transmission-of-virus-causing-covid-19-implications-for-ipc-precaution-recommendations

Organización Mundial de la Salud [OMS] (2020c). “Preguntas y respuestas sobre la enfermedad por coronavirus (COVID-19)". Consultado el 27 de noviembre de 2020 de: https://www.who.int/es/emergencies/diseases/ novel-coronavirus-2019/advice-for-public/q-a-coronaviruses

Organización Panamericana de la Salud [OPS] (2020). “14 de febrero de 2020: Nuevo coronavirus (COVID-19) - Actualización Epidemiológica". Consultado el 23 de noviembre de 2020 de: https://www.paho.org/hq/index.php?option=com_content\&view=article\&id=15725:14-february-2020novel-coronavirus-ncov-epidemiological-update\&Itemid=42346\&lang=es

OVACEN (2020). “Guía urbanística para luchar contra el Covid 19”. Consultado el 03 de diciembre de 2020 de: https://ovacen.com/guia-urbanistica-covid19/

Programa de las Naciones Unidas para el Desarrollo [PNUD] (2020). “Los impactos económicos del COVID-19 y las desigualdad de género: Recomendaciones y lineamientos de políticas públicas". Consultado el 27 de noviembre de 2020 de: https://r4v.info/es/documents/download/75940

Programa de las Naciones Unidas para el Medio Ambiente [PNUMA] (2020). "El PNUMA intensifica su trabajo para reducir los riesgos de pandemias a través de la protección ambiental". Consultado el 27 de noviembre de 2020 de:

https://www.unenvironment.org/es/noticias-y-reportajes/comunicado-de-prensa/ el-pnuma-intensifica-su-trabajo-para-reducir-los-riesgos

Qiu, Y.; Chen, X. \& Shi, W. (2020). “Impacts of social and economic factors on the transmission of coronavirus disease 2019 (COVID-19) in China". J. Popul. Econ., Vol. 33, pp. 1127-1172. doi: 10.1007/s00148-020-00778-2.

Ren, H.; Zhao, L.; Zhang, A.; Song, L.; Liao, Y.; Lu, W. \& Cui, C. (2020). “Early forecasting of the potential risk zones of COVID-19 in China's megacities". Sci. Total Environ., Vol. 729.

Rodríguez, I. (2020a). "Repensar el urbanismo como solución al cambio climático: caso de estudio: Área Metropolitana Asturiana". IV Congreso ISUF-H: Metrópolis en recomposición: prospectivas proyectuales en el Siglo XXI: Forma urbis y territorios metropolitanos, Barcelona, pp. 28-30. Consultado el 27 de noviembre de 2020 de: http://hdl.handle.net/2117/328891

Rodríguez, I. (2020b). "Las ciudades post-coronavirus: así va a transformar la pandemia el diseño urbano". EuroNews. Consultado el 27 de noviembre de 2020 de: https://es.euronews.com/2020/05/01/ las-ciudades-post-coronavirus-asi-va-ha-transformar-la-pandemia-el-diseno-urbano 
Rojas, D. (2020). “10 intervenciones en las ciudades que mitigan el contagio de la COVID-19 y a largo plazo mejoran la salud en general”. Instituto de Salud Global Barcelona. Consultado el 27 de noviembre de 2020 de: https://www.isglobal.org/healthisglobal/-/custom-blog-portlet/10-intervenciones-en-las-ciudadesque-mitigan-el-contagio-de-la-covid-19-y-a-largo-plazo-mejoran-la-salud-en-general/5083982/11701

Rojas, D. y Morales, E. (2020). “Urbanismo Táctico para COVID-19 intervenciones a corto plazo con una visión de salud a largo plazo". Colorado State University e Instituto de Salud Global de Barcelona. Consultado el 27 de noviembre de 2020 de: https://www.isglobal.org/documents/10179/7648746/ Urbanismo+tactico+es+infografia/944572a9-5566-42be-9c32-cf1a78414d25

Sharifi, A. (2019a). "Resilient urban forms: a macro-scale analysis". Cities, Vol. 85, pp. 1-14. doi: 10.1016/j. cities.2018.11.023.

Sharifi, A. (2019b). “Urban form resilience: a meso-scale analysis”. Cities, Vol. 93, pp. 238-252. doi: 10.1016/j. cities.2019.05.010.

Sharifi, A. \& Khavarian, A. (2020). “The COVID-19 pandemic: Impacts on cities and major lessons for urban planning, design, and management". Sci Total Environ, Vol. 749. Consultado el 25 de noviembre de 2020 de:

https://www.ncbi.nlm.nih.gov/pmc/articles/PMC7499053/

Vargas, R. (2020). Vida y proximidad, claves para abordar el impacto de la pandemia en la planeación de la ciudad informal post COVID-19. Revista Orinoquia, Ciencia y Sociedad, Vol. IV.

Xu, H. (2020). “Urban Development and Future Cities: Towards Building Back a Better Post COVID-19 Kuwait". United Nations Development Programme. Consultado el 27 de noviembre de 2020 de: https://www.undp.org/content/undp/en/home/news-centre/speeches/2020/urban-developmentand-future-cities-.html

Waller, A. \& Chakrabarti, M. (03 de agosto, 2020). "Cities That Heal: How The Coronavirus Pandemic Could Change Urban Design". On Point. Consultado el 27 de noviembre de 2020 de: https://www. wbur.org/onpoint/2020/08/03/healthy-cities-urban-design-pandemic

Wahba, S. y Vapaavuori, J. (2020). "A functional city's response to the COVID-19 pandemic". World Bank Blogs. Consultado el 27 de noviembre de 2020 de: https://blogs.worldbank.org/sustainablecities/ functional-citys-response-covid-19-pandemic

Zamorano, E. (11 de mayo, 2020). "Así sería la ciudad ideal para luchar contra pandemias como el covid-19". Alma, Corazón, Vida. Consultado el 27 de noviembre de 2020 de: https://www.elconfidencial.com/ alma-corazon-vida/2020-05-11/ciudad-ideal-coronavirus-covid-19-urbanismo_2589508/ 